\title{
Use of over-the-counter medicines: a window into chronic disease management by private medical insurance schemes in South Africa
}

Neelaveni Padayachee ( $\square$ neelaveni.padayachee@wits.ac.za)

University of the Witwatersrand https://orcid.org/0000-0002-6146-8702

Alan Dan Rothberg

University of the Witwatersrand Faculty of Health Sciences

Neil Butkow

University of the Witwatersrand Faculty of Health Sciences

Ilse Truter

Nelson Mandela University

Research article

Keywords: Medical Schemes, Over-the-counter medicine, Prescribed Minimum Benefits, chronic disease, disease management

Posted Date: August 9th, 2019

DOI: https://doi.org/10.21203/rs.2.12554/v1

License: () (1) This work is licensed under a Creative Commons Attribution 4.0 International License. Read Full License 


\section{Abstract}

Background In South Africa (SA) privately-insured individuals have easy access to over-the-counter (OTC) medicines. For patients registered with the insurer for management of a chronic disease through a disease management programme (DMP), the manner in which OTCs are accessed may provide insight into how well the disease is controlled and also how well the DMP is performing. Objective The study aimed to measure access to commonly-used OTC products by individuals registered for management of prevalent chronic diseases, and to consider why the medicines were selected in addition to mainstream drugs usually prescribed for treatment. Methodology Data were extracted from a large corporate database. Individuals of interest were aged $\geq 40$ years and registered for management of one of the prevalent non-communicable diseases. Utilization of aspirin, inhaled corticosteroids and bronchodilators was assessed. Results The study population included 4149 individuals registered for management of hypertension, hyperlipidaemia, Type 2 diabetes, asthma, chronic obstructive pulmonary disease, bronchiectasis, coronary artery disease, cardiomyopathy, cardiac failure, arrhythmia, vascular disease or glaucoma, and 12105 controls without any of the chronic conditions. The conditions were grouped together as metabolic, respiratory, cardiovascular or glaucoma. Whether accessed directly by individuals or prescribed by doctors, there was high utilisation of bronchodilators in the respiratory group, likely for supplementary management of disease. Bronchodilators were possibly accessed for management of side effects of medicines prescribed for treatment of cardiovascular disease. Bronchodilator access was also high among control subjects, possibly indicating that this group included those with asymptomatic or undiagnosed disease. Aspirin appeared to be appropriately utilised for management of cardiovascular and metabolic disease. All the OTC medicines were inappropriately funded out of the acute medicines benefit pool instead of being funded from the chronic medicines pool. Conclusions Disease management programmes are an integral part of managed care, which itself is written into legislation as a tool to mitigate clinical and financial risk within privately-funded medical insurance schemes. Analysis of OTC medicines accessed by DMP-registered individuals strongly suggests that DMPs are falling short in both clinical and financial areas. Routine system-driven claims analysis would enable insurers to develop performance-enhancing interventions.

\section{Introduction}

In South Africa private health insurance is provided by 78 entities known as medical schemes. Most provide cover for employees of corporate entities or employee groups such as trade unions, while a few are open to the general public. The industry covers some 8.9 million lives and is regulated by the government-constituted Council for Medical Schemes (CMS). Covered individuals are referred to as beneficiaries. In 1998 in order to ensure mandatory cover for all beneficiaries the South African Government promulgated Medical Schemes Act 131 and its associated Regulations. ${ }^{[1]}$ Managed care principles are embedded in the Act and applied in various ways by the medical schemes. Included in the legislation is a set of Prescribed Minimum Benefits (PMBs) that guaranteed funding for the diagnosis, treatment and ongoing care of 270 conditions considered urgent in nature, require hospitalization, represent 'a threat to life or limb' and are regarded as treatable within the local context. ${ }^{[1]}$ The associated Chronic Disease List (CDL) covers 26 chronic conditions and is prescriptive in terms of management, the emphasis being on treatment algorithms and drug therapy. ${ }^{[1]} \mathrm{A}$ key feature of the PMBs and CDL is the requirement for medical schemes to fund the designated services in full out of the risk pool, without co-payment.

In a comprehensive review that highlighted South Africa's quadruple burden of disease, Mayosi et al ${ }^{[2]}$ pointed out that much needed to be done to and for the country's health systems in order to strengthen primary healthcare, integrate care of chronic diseases and attend to risk factors. ${ }^{[2]}$ Their comments largely apply to the country's public health system which covers $>80 \%$ of the population, but in fact within the privately-funded medical schemes these elements exist to a greater or lesser extent in disease management programmes (DMPs). A major focus of DMPs is on non-communicable diseases, with the aim of preventing, diagnosing and treating conditions which range from highly-prevalent hypertension to haemophilia at the bottom end of the prevalence spectrum. ${ }^{[3]}$ As shown in a 2018 analysis of medical scheme beneficiary data routinely submitted to the CMS, the top 10 CDL conditions in 2015 were hypertension, hyperlipidaemia, Type 2 diabetes, asthma, hypothyroidism, coronary artery disease, cardiomyopathy, epilepsy, bipolar mood disorder and glaucoma. ${ }^{[3]}$ Medical scheme beneficiaries with one or more CDL conditions register with their medical scheme's relevant DMP in order to obtain a range of healthcare services (known as 'benefits') and funding for their disease/s. Benefit guides in the public domain reveal that disease management provided by DMPS is highly variable, ranging from simple access to advice, care guides and health brochures for

hypertension, hyperlipidaemia and asthma ${ }^{[4]}$, to comprehensive management of specific conditions such as diabetes, Human Immunodeficiency virus /Acquired Immunodeficiency syndrome(HIV/AIDS) and kidney failure. ${ }^{[5]}$ One particular programme puts particular effort into managing beneficiaries with multiple chronic diseases, employing staff to assist with access to appropriate care, and providing educational material to promote healthy lifestyle changes. ${ }^{[6]}$ The cost of DMPs is factored into the monthly contributions/premiums of all beneficiaries, this on the grounds that well-managed disease among affected individuals maintains their 
health, reduces morbidity and hospitalization, and ultimately achieves savings for all. ${ }^{[7,8]}$ As is the case with PMBs, services and care within the various DMPs are expected to be paid from the risk pool.[9]

For CDL conditions the mainstay of drug treatment is doctor-prescribed medicines as per treatment protocols ${ }^{[1]}$. The medicines typically appear as Schedule 3-6 drugs as defined by the South African Health Products Regulatory Authority (SAHPRA), the entity established by government to oversee the regulation of health products, including all medicines and controlled substances. ${ }^{[10]}$ The higher the schedule, the greater the restriction to access. Over-the-counter (OTC) medicines in lower schedules (0-2) may also be indicated for the CDL conditions. Whether in lower or higher schedules, when used for management of chronic diseases these medicines should be accessible via the risk pool and not paid for out of other 'funding pools' that typically have monetary limits and/or co-payments, and cover 'day-today' benefits such as out-of-hospital doctor consultations and services, and acute medicines. The acute medicines component includes OTC medicines prescribed by doctors or accessed by beneficiaries for purposes of self-medication.

Medical scheme beneficiaries access large quantities of OTC medicines, and utilization patterns and costs differ according to whether products are accessed by beneficiaries or prescribed by doctors. ${ }^{[11]}$ The focus in this analysis is on older, DMP-registered beneficiaries who were eligible for management of one of the CDL conditions and also for full funding of appropriate medicines via the risk pool. Our particular objective was to identify common OTC products accessed by these beneficiaries, and to consider why the lower-scheduled medicines might be selected. Literature exists from other countries showing the extent to which chronic disease patients access nonprescription medicines, sometimes in support of their care but often to their detriment. ${ }^{[12]}$

\section{Methodology}

Beneficiaries were selected from a database provided by a large South African medical scheme administration company. Such companies typically administer a number of medical schemes and are responsible for their operational needs, ranging from enrolment to call centre services, claims processing and actuarial services. De-identified demographic and claims data for 641535 beneficiaries were provided for a 12-month period (January - December 2015) by the company, which services a number of medical schemes that together cover over 3 million beneficiaries. Benefits vary between medical schemes, with each combination of medical, dental, hospital, medicines and other benefits constituting a 'plan' or 'option'. For the purposes of this study the beneficiaries of interest were drawn from four 'comprehensive' benefit plans with similarly rich/generous benefits in terms of scope, funding and access to health providers and services.

The CMS list of top CDL conditions was reviewed, and treatment algorithms and guidelines ${ }^{[1]}$ studied to identify OTC medicines that had a place in the management of the conditions. This resulted in the inclusion of 12 conditions that were assigned to one of four groups: metabolic syndrome/metabolic (hypertension, hyperlipidaemia, Type 2 diabetes); respiratory (asthma, chronic obstructive pulmonary disease, bronchiectasis), cardiovascular (coronary artery disease, cardiomyopathy, cardiac failure, arrhythmia, vascular disease) and glaucoma (Table 1). The specific diagnosis for each beneficiary as registered on the relevant DMP was directly extracted from the database. Only beneficiaries $\geq 40$ years of age were included, the age cut-off applied so as to also include early-onset chronic disease. Beneficiaries registered for more than one of the selected chronic conditions were excluded to eliminate 'overlap' as to why a particular OTC medicine might have been accessed. Beneficiaries aged $\geq 40$ years not registered for any of the chronic diseases formed the control group. Based on treatment algorithms and guidelines ${ }^{[1]}$ the OTC medicines for further study were aspirin, bronchodilators and inhaled glucocorticoids. Use of these products was extracted from the database as captured i.e. according to the Anatomical Therapeutic Chemical (ATC) classification which groups all products according to active substances, organ or system on which they act, and therapeutic, chemical or pharmacological properties. ${ }^{[13]}$ In the case of glaucoma the OTC medicines of interest were products containing anti-histamines which, according to guidelines, may aggravate the condition and should be avoided ${ }^{[14]}$. Additional information extracted for each beneficiary included gender, age, ethnicity and the cost of the OTC medicines as submitted to the medical schemes for payment.

Page $3 / 12$ 
At medical schemes level all medicine claims are captured according to how they were accessed by beneficiaries and paid by the medical

scheme. It was thus possible to identify whether the OTC medicines were prescribed by a doctor or accessed directly by beneficiaries. For purposes of this study the doctor-prescribed medicines are referred to as DP medicines, and those accessed by beneficiaries are referred to as BP. Data were then analysed for the four chronic disease groups and the control group. Access to the medicines of interest was assessed for each group, whether from the DP or BP category. Statistical analyses, carried out using Statistica (Version 13.2 TIBCO Software Inc., Palo Alto, CA, USA), included descriptive statistics, comparison of means, and frequency analysis. Significance was set at $\mathrm{p}<0.05$

\section{Results}

Details of the study population and the five groups are shown in Table 1. One-quarter (25.5\%) of the beneficiaries were formally registered for management of their chronic disease through a DMP. This is higher than the 20.1\% reported by the CMS for the same set of conditions within the total population of medical scheme beneficiaries, ${ }^{[3]}$ and is likely the result of this study focusing on beneficiaries aged $>40$ years. The breakdown by ethnicity is quite different from that reported by Statistics South Africa in 2018 [15] which showed that $72 \%$ of whites, $49 \%$ Asians, $20 \%$ mixed race and $10 \%$ of Black Africans belonged to a medical scheme. Differences are likely due to the nature of the medical schemes and beneficiaries selected for this study.

Table 1. Characteristics of the study population

\begin{tabular}{|l|l|}
\hline Age: years (SD) & \\
\hline Respiratory Group (n=247) & $55.2(11.7)$ \\
\hline Metabolic Group (n=3638) & $57.7(13.1)$ \\
\hline Cardiovascular Group (n=200) & $61.6(15.5)$ \\
\hline Glaucoma Group (n=87) & $63.8(17.1)$ \\
\hline Control Group (n=12108) & $53.9(11.6)$ \\
\hline Gender: $\mathbf{n}(\%)$ & \\
\hline Male & $7500(46.1 \%)$ \\
\hline Female & $8753(53.9 \%)$ \\
\hline Ethnicity: $\mathbf{n}(\%)$ & \\
\hline Black African & $2812(17.3 \%)$ \\
\hline Mixed race & $4975(30.6 \%)$ \\
\hline Asian & $1416(8.7 \%)$ \\
\hline White & $7007(43.1 \%)$ \\
\hline & \\
\hline Beneficiaries with one chronic disease:n(\%) & $4149(25.5 \%)$ \\
\hline Controls: $n(\%)$ & $12105(74.5 \%)$ \\
\hline
\end{tabular}

The specific medical conditions recorded on the medical schemes database and their contributions to the four chronic disease groupings are shown in Table 2. Also shown are the OTC medicines selected for study, and the sources that served as the basis for their selection. Aspirin-containing OTC products of interest fell into ATC category B01AC06, fluticasone was the only OTC inhaled glucocorticoid (ATC R01AD08), while OTC bronchodilators were identified in three ATC categories: salbutamol (R03AC02) and theophylline (R03DA20 and R03DA54). Theophylline represented $82.4 \%$ of the accessed bronchodilators. 
Table 2. Groups, chronic conditions and ОTC medicines of interest.

\begin{tabular}{|c|c|c|}
\hline Chronic group & Chronic diseases (\% contribution to group) & $\begin{array}{l}\text { OTC medicine/s of } \\
\text { interest }\end{array}$ \\
\hline Metabolic $(\mathrm{n}=3638)$ & Hypertension (69\%); Type 2 diabetes (14\%); Hyperlipidemia (13\%) & Aspirin $^{[18]}$ \\
\hline $\begin{array}{l}\text { Respiratory } \\
(\mathrm{n}=247)\end{array}$ & Asthma (90\%); Chronic Obstructive Pulmonary Disease/Bronchiectasis (8\%) & $\begin{array}{l}\text { Fluticasone, } \\
\text { Theophylline, } \\
\text { Short-acting } \beta_{2} \\
\text { agonists }\end{array}$ \\
\hline $\begin{array}{l}\text { Cardiovascular } \\
(\mathrm{n}=200)\end{array}$ & $\begin{array}{l}\text { Ischemic heart disease (31\%); Congestive heart failure (31\%); Vascular disorders (31\%); } \\
\text { Arrhythmia (5\%) }\end{array}$ & $\begin{array}{l}\text { Aspirin }^{[18]} \\
{\text { Short-acting } \beta_{2}} \\
\text { agonists, } \\
\text { Theophylline }\end{array}$ \\
\hline Glaucoma $(n=87)$ & Glaucoma & Anti-histamines $^{[14]}$ \\
\hline
\end{tabular}

For each of the chronic disease groups the breakdown by gender showed that males were affected to a greater extent than females for all except the cardiovascular group (Figure 1). Disease rates were highest for white beneficiaries and lowest for Black Africans. Prevalence of respiratory disease was almost three times higher for Asians than for Black Africans. It is important to note that these figures for prevalence were not based on population-based surveys or screening programmes and as such may hide significant numbers of asymptomatic and/or undiagnosed disease.

Figure 2 shows the percentage of beneficiaries within the four chronic disease categories and the control group. Among glaucoma patients the use of antihistamines was indeed significantly lower than in the control group (41.3\% vs. 54.5\%; p<0.02) but there was also clear indication that these medicines were not avoided as per recommendations. ${ }^{[14]}$ Of particular interest was the use of aspirin and bronchodilators by patients with glaucoma. Both medicines were accessed by almost 15\% of the group. Beneficiaries within the respiratory group showed almost no use of aspirin, while bronchodilators were accessed by more than one-third of patients. Beneficiaries within the metabolic, cardiovascular and control groups showed very similar profiles of fairly low use of aspirin, similar access to fluticasone, and use of bronchodilators by about $20 \%$. The latter finding raises the question of whether the control group was indeed representative of beneficiaries without any of the chronic diseases under review. For this study beneficiaries within the four chronic disease categories were identified on the basis of registration with one of the medical scheme DMPs; it therefore follows that beneficiaries with undiagnosed disease might have accessed medicines to the same extent as those with DMP-registered disease, but were not reflected/recorded on the database as suffering from one of the index conditions.

As shown in Figure 3, utilization rates of OTC medicines in the doctor-prescribed category were higher than when beneficiaries accessed on their own (also shown in Table 3). Patients in the cardiovascular group had the lowest prescription rate for bronchodilators but the highest for aspirin. This rate for prescription of aspirin is similar to that identified by the Health Quality Assurance organization (HQA) that monitors performance of medical schemes and healthcare providers ${ }^{[16]}$ and is also in accordance with international guidelines for management of the conditions that are included in the category. ${ }^{[17]}$ In the respiratory group $>60 \%$ of patients received OTC bronchodilators and $>50 \%$ received fluticasone. The moderate prescription rate of aspirin for patients in the metabolic group is also in line with international guidelines that recommend aspirin for patients at increased risk for cardiovascular events. ${ }^{[17]}$ In the glaucoma group aspirin was prescribed for some $40 \%$ and bronchodilators for $20 \%$. As already discussed for the BP medicines, similar utilization of the medicines by the control, metabolic and respiratory groups raises the question of whether beneficiaries in the control group did indeed have one of the chronic diseases but were not registered on the medical scheme DMP. At medical scheme level they would have been regarded as free of chronic disease, while at doctor level they may have been diagnosed and treated.

When all the OTC medicines of interest are combined, as shown in Table 3 there were significantly higher numbers of beneficiaries who accessed OTC medicines via a doctor's consultation and prescription than on their own $(\mathrm{p}<0.0001)$. 
Table 3. Percentage of beneficiaries in Chronic Disease and Control groups accessing OTC medicines directly vs. via a doctors' prescription

\begin{tabular}{|l|l|l|}
\hline Group & \% Beneficiary-accessed (BP) & \% Doctor-prescribed (DP) \\
\hline Chronic Disease $(n=4172)$ & 30.0 & 72.5 \\
\hline Controls $(n=12108)$ & 30.1 & 53.7 \\
\hline
\end{tabular}

-

\section{Discussion}

Access to OTC medicines is often presented as a cost-saving mechanism that allows members of the public to self-treat minor ailments rather than consult a doctor; ${ }^{[18]}$ however, there are also roles for various of these medicines in the management of chronic diseases. In the present study the focus was on utilization of OTC medicines applicable to the management of a selection of chronic diseases prevalent among medical scheme beneficiaries $\geq 40$ years of age, formally registered with an appropriate DMP. As shown in Table $2,22.5 \%$ of beneficiaries were in the metabolic category, $1.5 \%$ were categorised as respiratory, $0.12 \%$ as cardiovascular and $0.5 \%$ as glaucoma. This distribution is similar to that reported by CMS for the same conditions. ${ }^{[3]}$

The analysis of chronic disease group according to gender and ethnicity (Figure 1) showed results at odds with national data. The higher rate of females in the cardiovascular group differs from that shown in the CMS report which reflected a male:female ratio of 1.4:1,[3] while the prevalence of diseases among ethnic groups differs from national statistics. ${ }^{[15]}$ It is important to note that the various disease prevalence rates were not based on surveys or screening programmes that would have identified actual prevalence rates and/or asymptomatic/undiagnosed disease. Furthermore, recording of chronic diseases in the medical schemes environment is typically influenced by health-seeking behaviour of different groups. This has been studied in the South African context, showing that female gender, higher levels of education and ethnicity (whites in particular) are directly related to access to health services and treatment. ${ }^{[19]}$ Also important is that this study focused on DMP-registered chronic conditions; in the absence of registration the condition would not have been identified and recorded.

Utilization of OTC medicines accessed directly by beneficiaries is shown in Figure 2. In keeping with their disease, 5\% of respiratory patients accessed fluticasone and one-third accessed bronchodilators. The latter is of some concern since theophylline (the dominant bronchodilator in this study) is not regarded as mainstream treatment for asthma, although it might have a role in disease that is difficultto-control. ${ }^{[20]}$ Aspirin was accessed by a very small percentage of respiratory patients, possibly reflective of avoidance because of the effect of aspirin as a trigger for asthma. ${ }^{21]}$ Between 17 and 22\% of patients with diagnosed metabolic and cardiovascular conditions accessed bronchodilators. Here there is the possibility that they accessed the medication for self-treatment of a side-effect of treatment for their underlying disease. A beta-blocker prescribed for a cardiovascular patient with heart failure or arrhythmia is known to cause bronchoconstriction in some, resulting in use of a bronchodilator for management of the symptom. ${ }^{[22-23]}$ Bronchodilators contained in 'cough mixtures' may also have been accessed by hypertensive patients in the metabolic group who had a cough resulting from treatment with an angiotensin-converting-enzyme (ACE) inhibitor. ${ }^{[24]}$ The similar utilization between subjects in the metabolic and control groups has raised the question of undiagnosed disease in the latter. This is highly likely given that all three conditions within the metabolic group (hypertension, Type 2 diabetes and hyperlipidaemia) are known to be undiagnosed on a large scale, both nationally and globally. In this regard, studies in the sub-Saharan region have shown a 15-76\% rate of undiagnosed hypertension, while globally $45.8 \%$ have undiagnosed diabetes. ${ }^{[25-26]}$ Around 15\% of glaucoma patients accessed aspirin and bronchodilators. While neither medicine has a place in mainstream management of glaucoma, data have shown that the different types of glaucoma may benefit from these medicines. ${ }^{[27-29]}$ Several thousand beneficiaries in this study had a chronic disease registered for management by a medical scheme DMP which should have overseen all elements necessary for disease control, including funding of OTC/acute medicines. These requirements are detailed in legislation ${ }^{[1]}$ and in the CMS Accreditation Standards for Managed Care Organizations. ${ }^{[9]}$ 
Prescription of OTC medicines by doctors for beneficiaries in the four groups is shown in Figure 3. In the respiratory group there was again high prescription of fluticasone and bronchodilators. Both medicines should have been funded from the risk pool, and one must question what the DMP was actually managing. Higher-scheduled medicines are the mainstay of treatment for the respiratory conditions,

[1] therefore the resort to OTC medicines, theophylline in particular, suggests that disease control might have been inadequate. In comparison with the minimal aspirin utilization rate when patients self-medicated, the $20 \%$ prescription rate by doctors was fairly high, particularly since there is the known role for aspirin as an asthma trigger. ${ }^{[21]}$ This is worthy of further investigation. However in the cardiovascular group there was appropriately-high prescription of aspirin, consistent with guidelines for secondary prevention in conditions such as ischaemic heart disease, vascular disease and arrhythmias. ${ }^{[17]}$ Despite its low cost, aspirin should also have been funded as a chronic medication. The prescription of aspirin to almost $40 \%$ of patients in the metabolic group was also in line with guidelines, for example for diabetics with risk factors for cardiovascular disease. ${ }^{[17]}$ The prescription of bronchodilators for $20 \%$ of metabolic group patients could again have been for treatment of side effects such as an ACE-inhibitor cough. ${ }^{[24]}$ The control group had a $40 \%$ prescription rate for aspirin and $22 \%$ rate for bronchodilators, possibly for 'undiagnosed' disease, but in this category of doctorprescribed medicines it is more likely that doctors were treating a condition that had been diagnosed but not registered with the medical scheme. The high prescription rate of aspirin and $20 \%$ rate of bronchodilators to glaucoma patients were possibly for the reasons already mentioned for the beneficiary-accessed medicines.

A number of concerns arise out of this study, the first being that OTC medicines were accessed for the treatment of DMP-registered conditions and not fully funded out of the chronic medicines benefit. In some cases the OTC medicine was entirely appropriate (e.g. aspirin for cardiovascular patients), in others it was perhaps less-appropriate (e.g. theophylline for asthma patients who could/should have been better managed with first-line drugs), and in a third category it might have served as a 'flag' warranting further investigation (aspirin for glaucoma patients). The CMS is clear on the criteria for accreditation of managed care organizations and their DMPs, ${ }^{[9]}$ but precisely how these programmes operate is variable. ${ }^{[4-6]}$ Diabetes management is typically multi-dimensional with programmes offered by medical schemes or outsourced to a dedicated service provider that enrols patients, schedules regular access to doctors, nurses, nutritionists and biokineticists, and provides medicines and laboratory tests relating to diabetes control. ${ }^{[8]}$ On the other hand, hypertension is the most prevalent condition but DMP management is usually limited to approval of chronic medicines, access to brochures, and the occasional telephone call from the medical scheme. ${ }^{[4]}$ Whether a comprehensive or a more-basic DMP it is well within the capability of medical scheme administrators and their DMPs to interrogate claims data and maximise the value ${ }^{[30,31]}$. Claims for medicines other than the mainstream higher-scheduled drugs would be identified and if linked in any way to the particular chronic condition a call could be made as to whether disease was inadequately controlled or medicines administered to treat side effects of other drugs. Beneficiaries and/or their doctors could also be contacted for information as to why particular OTC medicines were being accessed, whether for supplementary disease control or to treat side effects such as cough or wheezing. Interrogation of the use of aspirin and bronchodilators by and for glaucoma patients might shed interesting light on the condition and its management, while a review of OTC claiming patterns in apparently-healthy beneficiaries would likely alert and inform medical schemes of the need to screen for undiagnosed conditions such as hypertension and diabetes. Table 3 condenses data from the study into various categories, showing whether OTC medicines in this study were accessed directly by beneficiaries or prescribed by a doctor, and whether beneficiaries were DMP-registered or apparently free of the chronic conditions studied. The $30 \%$ of beneficiaries with a registered disease who directly accessed OTCs were likely those whose disease was under-treated or were self-medicating for side effects of recommended treatment. The $72.5 \%$ for whom OTC medicines were prescribed by doctors were likely in similar categories (under-treated or treated for sideeffects). In both cases the DMPs were falling short in their responsibilities, while the CMS should also be held to account for poor oversight of DMPs that they have accredited. The 30.1\% of control beneficiaries who directly accessed OTCs likely included those with undiagnosed disease. This category should be managed by medical schemes through 'wellness days' that offer screening for common conditions such as diabetes, hypertension, hyperlipidaemia, asthma and cardiac dysfunction. For the $53.7 \%$ of control beneficiaries for whom the OTC medicines were prescribed by doctors one may speculate that the doctors were aware of the various conditions, but between themselves and their patients had failed to have the diseases registered with the medical schemes. Recognizing that DMPs are 
paid for by beneficiaries, management failures such as the above are breaches, not only of trust but also of contracts between beneficiaries and their medical schemes.

\section{Limitations}

This study involved beneficiaries of a subset of medical schemes administered by one administration company. Results and observations may therefore not be applicable to the broader industry. In the interpretation of the data some postulates are presented, for example OTC bronchodilators accessed or prescribed to treat side effects of mainstream drugs used for cardiovascular disease. Evidence supports such postulates, ${ }^{[22-24]}$ but it was not possible to confirm the associations in this study because the beneficiary database was limited to OTC medicines. No such limitation exists at medical scheme level and all associations could be explored with the potential to yield both clinical and financial benefits.

\section{Conclusions}

Disease management programmes are an integral part of managed care which itself is written into legislation as a tool to mitigate clinical and financial risk within medical schemes. ${ }^{[1]}$ Our analysis of OTC medicines accessed by DMP-registered beneficiaries strongly suggests that DMPs are falling short in both clinical and financial areas. Routine system-driven claims analysis would enable medical schemes to develop performance-enhancing interventions.

\section{Abbreviations}

DMP- Disease management programme

OTC- Over-the-counter

CMS - Council of Medical schemes

PMB- Prescribed Minimum Benefits

CDL- Chronic Disease List

SAHPRA- South African health products regulatory authority

ATC- anatomical therapeutics chemical

ACE- Angiotensin- converting Enzyme

BP- Beneficiary purchased

DP- Doctor prescribed

HIV- Human Immunodeficiency Virus

AIDs- Acquired Immunodeficiency Disease

\section{Declarations}

Ethics: Ethics approval was obtained from the Human Ethics Committee of the University of the Witwatersrand (certificate M160141).

Consent for publication: Not Applicable

Availability of data and materials: The data that support the findings of this study are available from the administrator but restrictions apply to the availability of these data, which were used under license for the current study, and so are not publicly available. Data are however available from the authors upon reasonable request and with permission of the administrator.

Competing interests: The authors declare that they do not have any competing interests. 
Funding: None

Author contributions: NP and AR conceptualised the study, methodology and analysis. IT and NB contributed to the final draft of the study.

Acknowledgements: The authors acknowledge the assistance of the medical schemes administrator in providing the database

\section{References}

1. Medical Schemes Act 131 of 1988. https://www.gov.za/sites/default/files/gcis_document/201409/a131-98.pdf (accessed 24 June 2019)

2. Mayosi BM, Flisher AJ, Lalloo UG et al. The burden of non-communicable diseases in South Africa. The Lancet. 2009;374(9693):934947. https://doi.org/10.1016/s0140-6736(09)61087-4

3. Govuzela M et al. Prevalence of chronic disease in the population covered by medical schemes in South Africa. Council of Medical Schemes. https://medicalschemes.com (accessed 24 June 2019)

4. Disease Management. Government Employees Medical Scheme https://www.gems.gov.za/en/members/programmes/diseasemanagement (accessed 24 June 2019)

5. Chronic Illnesses and other medical conditions. Discovery Health Medical Scheme https://www.discovery.co.za/medical-aid/chronicillnesses-other-medical-conditions (accessed 24 June 2019)

6. Beneficiary Risk Management. Medscheme. http://www.medscheme.com/products-and-services/health-administration/integrateddisease-management/(accessed 20 June 2019)

7. Aid for AIDS. http://www.aidforaids.co.za/about.php(accessed 19 June 2019)

8. Core Concepts in Diabetes Mellitus. Centre for Diabetes and Endocrinology http://web.cdediabetes.co.za/about-cde/ourhistory(accessed 21 June 2019)

9. Accreditation Standards for Managed Care Organisations. Council of Medical Schemes. https://www.medicalschemes.com/files/Guidelines\%20and\%20Manuals/Standard\%20doc\%20managed\%20care\%20final\%2022\%20Oc (accessed 24 June 2019)

10. Consolidated Schedules. South African Health Products Regulatory Authority. https://www.sahpra.org.za/documents/f6bf8a532016_Consolidatedschedules2008200920112012201320142015March_May2016(inclu (accessed 22 June 2019)

11. Padayachee N, Rothberg AD, Truter I, Butkow N. Utilization of over-the-counter analgesics in two private medical insurance schemes in South Africa. Drug Healthcare Patient Saf. 2019;11:37-45.

12. Qato DM. Alexander GC, Conti RM et al. Use of prescription and over-the-counter medications and dietary supplements among older adults in the United States. JAMA. 2008; 300(24):2867-2878. https://doi.org/10.1001/jama.2008.892

13. Anatomic and Therapeutic Classification. World Health Organisation. https://www.who.int/medicines/regulation/medicinessafety/toolkit_atc/en/(accessed 19 June 2019)

14. Is it safe to take anti-histamines if you have glaucoma. The Glaucoma Foundation.

https://www.glaucomafoundation.org/info_new.php?id=156\&cat=11\#173 (accessed 24 June 2019)

15. Mid-year population estimates 2018. Statistics South Africa. https://www.statssa.gov.za/publications/P0302/P03022018.pdf (Accessed 24 June 2019)

16. Health Quality Assessment Newsletters. Health Quality Assessment. https://www.hqa.co.za/newsletters

17. Cardiovascular disease and risk management: standards of medical care in diabetes. American Diabetes Association. Diabetes Care. 2018;41(Supplement 1):S86-104. https://doi.org/10.2337/dc18-s009 
18. Dalton K, Byrne S. Role of the pharmacist in reducing healthcare costs: current insights. Integr Pharm Res Prac. 2017;6:37. https://doi.org/10.2147/iprp.s108047

19. Abaerei, Admas Abera. Factors affecting health-care seeking behaviour, and assessment of the population's perception of the major health problems in Gauteng province, South Africa 2013. MSc Dissertation, University of the Witwatersrand http://wiredspace.wits.ac.za/handle/10539/21533(accessed 17 June 2019)

20. Barnes PJ. Theophylline. Am J Resp Crit CareMed 2013;188(8):901-6. https://doi.org/10.1164/rccm.201302-0388pp

21. Narayanankutty A, Reséndiz-Hernández JM, Falfán-Valencia R, Teran LM. Biochemical pathogenesis of aspirin exacerbated respiratory disease (AERD). Clin Biochem. 2013;46(7-8):566-578. https://doi.org/10.1016/j.clinbiochem.2012.12.005

22. Lewis RV, Lofthouse C. Adverse reactions with $\beta$-adrenoceptor blocking drugs. Drug Saf. 1993;9(4):272-279. https://doi.org/10.2165/00002018-199309040-00005

23. Carvedilol side effect:cough. eHealthMe. https://www.ehealthme.com/ds/carvedilol/cough (accessed 24 June 2019)

24. Simon SR, Black HR, Moser M, Berland WE. Cough and ACE inhibitors. Arch Int Med. 1992;152(8):1698-1700. doi:10.1001/archinte.1992.00400200128023

25. Ataklte F, Erqou S, Kaptoge S, et al. Burden of undiagnosed hypertension in sub-Saharan Africa: a systematic review and metaanalysis. Hypertension. 2015;65(2):291-298. https://doi.org/10.1161/hypertensionaha.114.04394

26. Beagley J, Guariguata L, Weil C, Motala AA. Global estimates of undiagnosed diabetes in adults. Diabetes Res Clin Prac. 2014;103(2):150-60. https://doi.org/10.1016/j.diabres.2013.11.001

27. Attarzadeh A, Hosseini H, Nowroozizadeh S. Therapeutic potentials of aspirin in glaucomatous optic neuropathy. Med hypotheses. 2006;67(2):375-7. https://doi.org/10.1016/j.diabres.2013.11.001

28. Zimmerman TJ. Topical ophthalmic beta-blockers: a comparative review. J Ocul Pharmacol Ther. 1993;9(4):373-84. https://doi.org/10.1089/jop.1993.9.373

29. Waldock A, Snape J, Graham CM. Effects of glaucoma medications on the cardiorespiratory and intraocular pressure status of newly diagnosed glaucoma patients. Br J Ophthalmol 2000;84(7):710-3. https://doi.org/10.1136/bjo.84.7.710

30. Rothberg AD, Matshidze PK. Perimenopausal wrist fracture--an opportunity for prevention and management of osteoporosis. S Afr Med J. 2000;90:1121-4

31. Rothberg AD, Matshidze PK. Monitoring and management of bone status in patients on chronic glucocorticoid treatment--the Medscheme experience. S Afr Med J. 2000; 90:1125-9

\section{Figures}




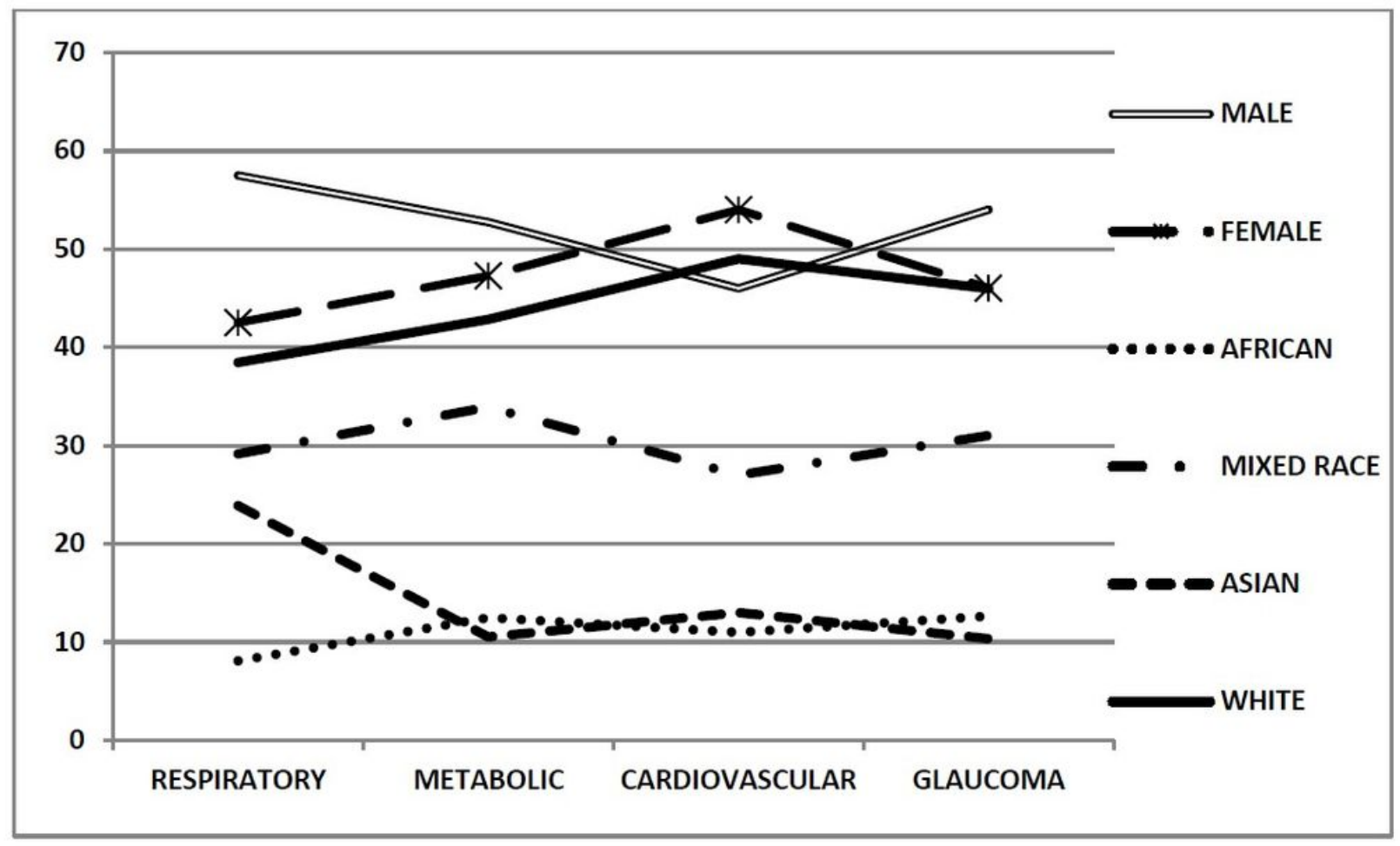

Figure 1

Beneficiaries per chronic disease group by gender and ethnicity

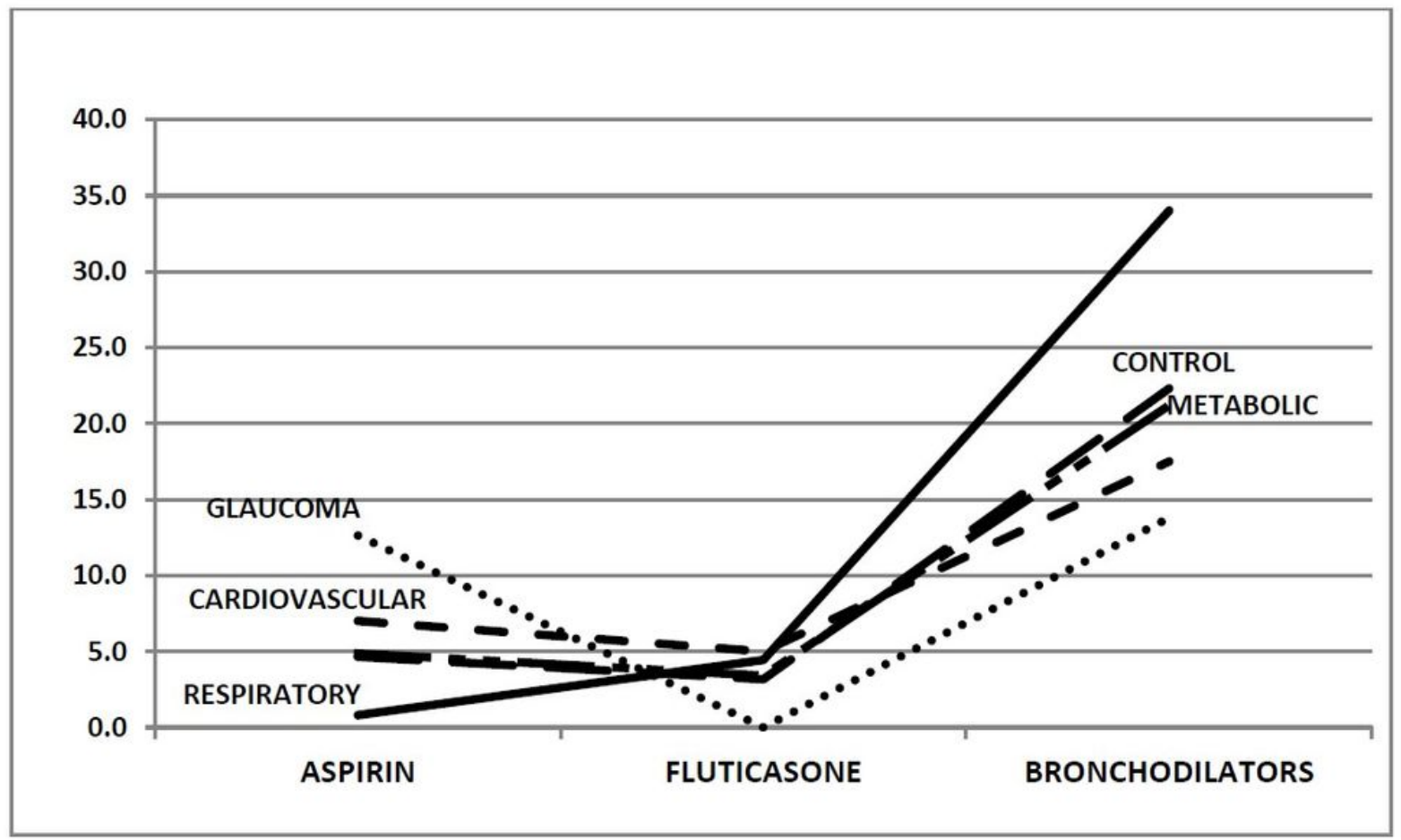

Figure 2

OTC Medicines accessed directly by beneficiaries (BP category) 


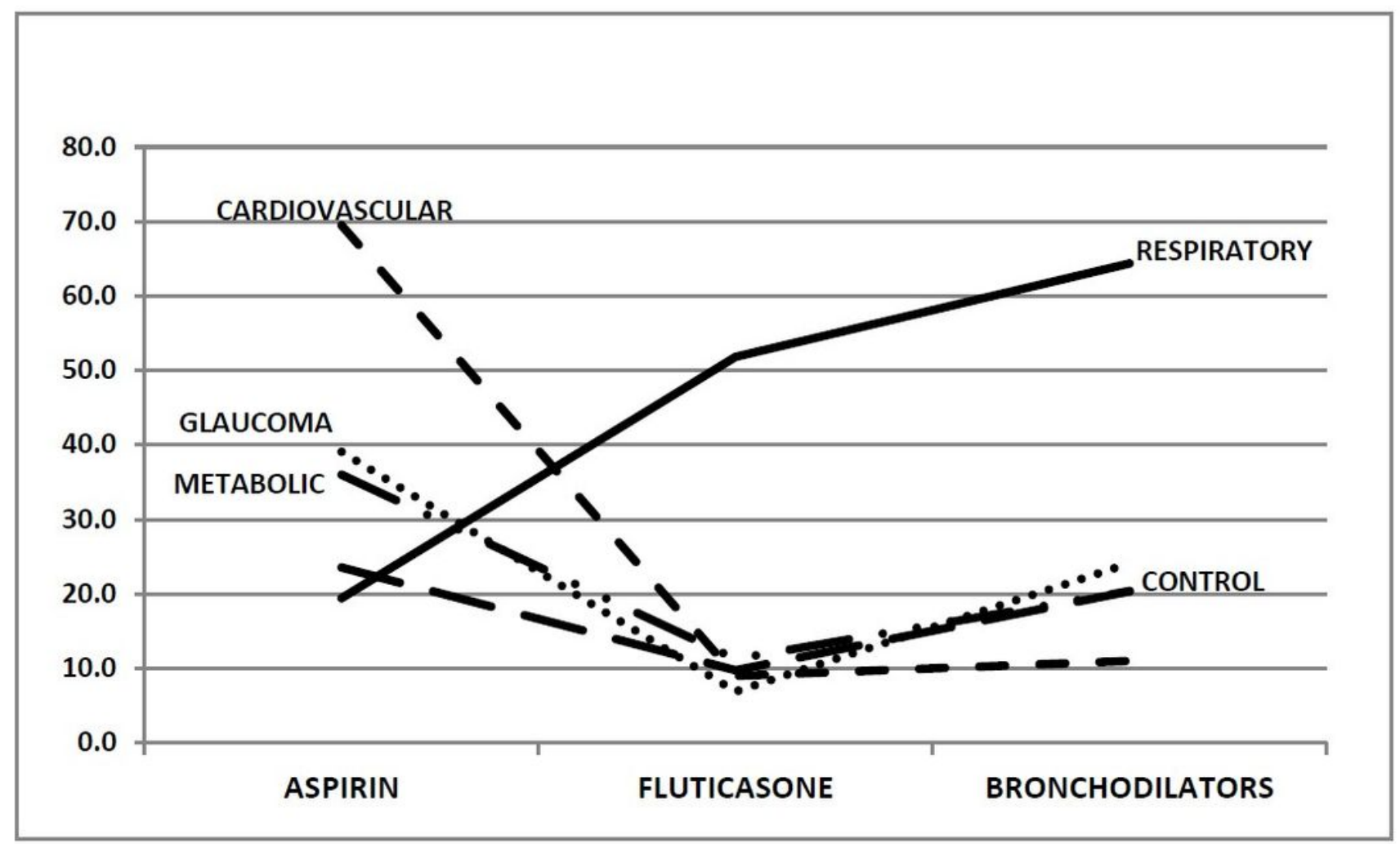

Figure 3

OTC Medicines included in a doctor's prescription (DP category) 